\title{
Crystal structure of release factor RF3 trapped in the GTP state on a rotated conformation of the ribosome
}

\author{
JIE ZHOU, LAURA LANCASTER, SERGEI TRAKHANOV, ${ }^{1}$ and HARRY F. NOLLER ${ }^{2}$ \\ Center for Molecular Biology of RNA and Department of Molecular, Cell and Developmental Biology, University of California at Santa Cruz, \\ Santa Cruz, California 95064, USA
}

\begin{abstract}
The class II release factor RF3 is a GTPase related to elongation factor EF-G, which catalyzes release of class I release factors RF1 and RF2 from the ribosome after termination of protein synthesis. The $3.3 \AA$ crystal structure of the RF3.GDPNP.ribosome complex provides a high-resolution description of interactions and structural rearrangements that occur when binding of this translational GTPase induces large-scale rotational movements in the ribosome. RF3 induces a $7^{\circ}$ rotation of the body and $14^{\circ}$ rotation of the head of the $30 \mathrm{~S}$ ribosomal subunit, and itself undergoes inter- and intradomain conformational rearrangements. We suggest that ordering of critical elements of switch loop I and the P loop, which help to form the GTPase catalytic site, are caused by interactions between the $G$ domain of RF3 and the sarcin-ricin loop of $23 S$ rRNA. The rotational movements in the ribosome induced by RF3, and its distinctly different binding orientation to the sarcin-ricin loop of 23S rRNA, raise interesting implications for the mechanism of action of EF-G in translocation.
\end{abstract}

Keywords: translation; GTPase; termination; translocation; switch loop; domain rearrangement

\section{INTRODUCTION}

Advances in elucidation of ribosome structure at the all-atom scale have provided a rich description of the molecular architecture of these very large molecular complexes (Schuwirth et al. 2005; Korostelev et al. 2006; Selmer et al. 2006). Despite this wealth of structural information, our knowledge falls short of an understanding of the mechanism of protein synthesis at the molecular level. This is because the structural complexity of the ribosome is compounded by its conformational dynamics, which are essential to its function (Korostelev et al. 2008b; Munro et al. 2009; Dunkle and Cate 2010; Frank and Gonzalez 2010). The importance of ribosome dynamics is highlighted by observations from several different approaches, including cryo-electron microscopy (cryo-EM) (Frank and Agrawal 2000; Fischer et al. 2010; Ratje et al. 2010), X-ray crystallography (Ogle et al. 2001; Schuwirth et al. 2005; Korostelev and Noller 2007; Zhang et al. 2009) and Förster resonance energy transfer (FRET) (Ermolenko et al. 2007a; Cornish et al. 2008, 2009; Fei et al. 2008; Marshall et al. 2008; Munro et al. 2010). Among the different modes of ribosome movement,

\footnotetext{
${ }^{1}$ Present address: Max Planck Institute for Biophysical Chemistry, Am Fassberg 11, 37077 Göttingen, Germany.

${ }^{2}$ Corresponding author.

E-mail harry@nuvolari.ucsc.edu.

Article published online ahead of print. Article and publication date are at http://www.rnajournal.org/cgi/doi/10.1261/rna.031187.111.
}

one of the most well known is the large-scale rotation between the $30 \mathrm{~S}$ and $50 \mathrm{~S}$ subunits, first observed in cryo-EM reconstructions of ribosomes bound with elongation factor EF-G (Frank and Agrawal 2000). Counter-clockwise rotation has been correlated with movement of tRNAs into hybrid states (Moazed and Noller 1989; Spiegel et al. 2007; Agirrezabala et al. 2008; Julian et al. 2008; Dunkle et al. 2011) and has been proposed to be the basis of a ratcheting mechanism responsible for the coupled translocation of mRNA and tRNA during protein synthesis (Frank and Agrawal 2000; Valle et al. 2003; Frank et al. 2007). Beside intersubunit movement, there is good evidence for rearrangement of many subfeatures of the large and small ribosomal subunits, including the head of the $30 \mathrm{~S}$ subunit, the L1 stalk, the L11 stalk, and even separate domains of the tRNAs during ribosome function. The challenge is to determine precisely how and when these movements occur, and to understand how they contribute to the mechanisms of translation.

Counter-clockwise intersubunit rotation is induced in response to binding of EF-G (Frank and Agrawal 2000), ribosome recycling factor (RRF) (Gao et al. 2005; Dunkle et al. 2011), or the class II release factor RF3 (Klaholz et al. 2004; Ermolenko et al. 2007a; Gao et al. 2007), a GTPase structurally related to EF-G that is responsible for promoting dissociation of the class I release factors RF1 and RF2 from the ribosome following termination (Goldstein and Caskey 1970; Freistroffer et al. 1997; Klaholz 2011). Although these con- 
formational changes in the ribosome are stabilized by interactions with translation factors, they appear to be inherent dynamic properties of the ribosome. For example, both intersubunit rotation and movement of the L1 stalk occur spontaneously in the absence of factors or GTP, and thus can be driven by thermal energy alone (Cornish et al. 2008, 2009; Fei et al. 2008). Elongation factor EF-Tu is not known to cause rotation (Allen et al. 2005; Schmeing et al. 2009), yet the conserved G domains of all of the GTPase factors bind to the sarcin-ricin loop (SRL) of $23 \mathrm{~S}$ rRNA and share other common ribosomal binding surfaces. How interactions with these translation factors induce large-scale conformational changes in the ribosome, how these dynamic events enable basic ribosomal functions, and the role of GTP hydrolysis in the diverse functions of these factors are all poorly understood.

Here, we present the $3.3 \AA$ crystal structure of the $70 \mathrm{~S}$ ribosome bound with RF3 and the nonhydrolyzable GTP analog GDPNP. Binding of the factor induces a $7^{\circ}$ rotation of the $30 \mathrm{~S}$ subunit relative to the $50 \mathrm{~S}$ subunit and a $14^{\circ}$ rotation of the head of the $30 \mathrm{~S}$ subunit relative to its body. These resulting large-scale structural rearrangements are predicted to distort or disrupt interactions that are responsible for binding of the class I release factors, explaining catalysis of their release by RF3. RF3 itself undergoes major inter- and intradomain conformational rearrangements between its free GDP state and its ribosome-bound GDPNP state. In our structure, the functionally important switch loop I is well ordered, allowing the first description of the interactions of the active site of the RF3 GTPase with GDPNP. Interestingly, the orientation of the $\mathrm{G}$ domain of RF3 relative to the $50 \mathrm{~S}$ ribosomal subunit is distinctly different from that observed for EF-G.GDP, EF-Tu-GDP, or EF-Tu-GDPCP (Gao et al. 2009; Schmeing et al. 2009; Voorhees et al. 2010), suggesting the possibility of the existence of more than one binding mode for the G domains of the GTPase translation factors during different stages of their interactions with the ribosome. Finally, the observed ribosomal conformational rearrangements result in opening of the constriction between the head and platform of the $30 \mathrm{~S}$ subunit that obstructs movement of the tRNA anticodon stem-loop (ASL), between the $\mathrm{P}$ and $\mathrm{E}$ sites (Schuwirth et al. 2005), and causes displacement of features of $16 \mathrm{~S}$ rRNA that contact the anticodon stem of P-site tRNA by a distance closely matching that required for movement of the ASL from the P site to the E site. This is an observation that may have implications for the molecular mechanics of translocation.

\section{RESULTS}

\section{Structural rearrangements of the ribosome}

Complexes of Escherichia coli 70 S ribosomes bound with $E$. coli RF3 were formed in the presence of GDPNP, mRNA, and tRNA as described in the Materials and Methods section. Under the solution conditions used for crystallization, tRNA dissociated from the complex (Supplemental Fig. S1), but mRNA remained bound. The complex crystallized in space group P2 $2_{1} 2_{1} 2_{1}$ with cell dimensions $257.6 \times 312.9 \times 328.6 \AA$ containing a single $70 \mathrm{~S}$ ribosome per asymmetric unit, a previously unobserved ribosome crystal form. The $3.3 \AA$ electron density map reveals well-resolved features of the rRNA, r-proteins, and RF3.GDPNP (Fig. 1; Supplemental Fig. S2), although parts of the $30 \mathrm{~S}$ subunit head and the L1 stalk are less well-ordered. There is clear density for the pentameric complex of proteins $\mathrm{L} 10(\mathrm{~L} 12)_{4}$, in which the structures of L10 and the N-terminal domains of the four L12 molecules can be fitted (Supplemental Fig. S3A). The orientation of the $\mathrm{L} 10(\mathrm{~L} 12)_{4}$ complex is rotated by $\sim 60^{\circ}$ around a hinge point between the globular N-terminal domain of L10 and its long, C-terminal $\alpha$-helix, relative to that seen in the 70S ribosome.EF-G complex (Gao et al. 2009). This was the only previous $70 \mathrm{~S}$ ribosome crystal structure in which the L10(L12) pentamer was observed (Supplemental Fig. S3B,C).

$\mathrm{RF} 3$ induces large-scale rotational movements of the head and body of the $30 \mathrm{~S}$ subunit, and other smaller conformational changes in both ribosomal subunits compared with the classical-state ribosome (we refer to the classical-state RF2 termination complex for comparison unless otherwise noted) (Fig. 2). The body of the $30 \mathrm{~S}$ subunit is rotated $7^{\circ}$ counter-clockwise relative to the $50 \mathrm{~S}$ subunit, as viewed from the $30 \mathrm{~S}$ solvent face (Fig. 2A), around an axis of rotation perpendicular to the subunit interface centered

A

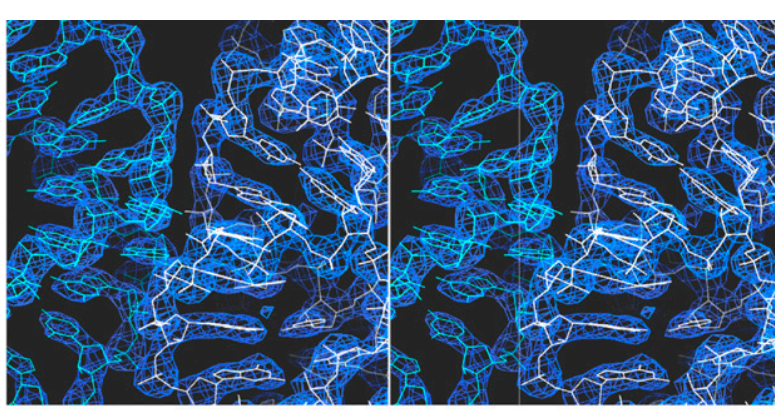

B

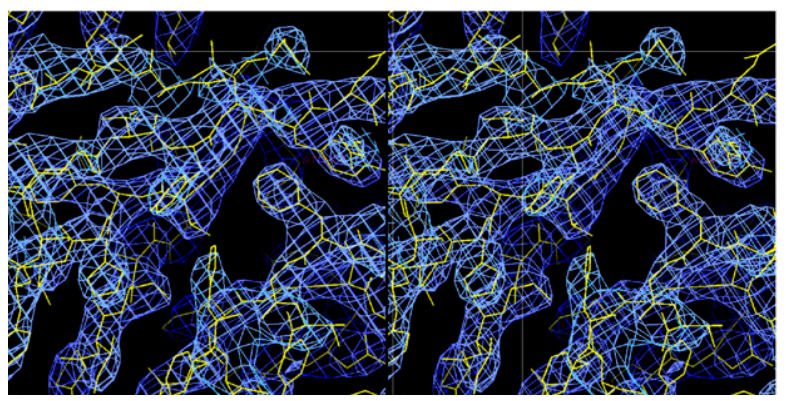

FIGURE 1. Example of electron density maps. (A) Electron density for rRNA. Stereo view of $3.3 \AA$ resolution $2 \mathrm{~F}_{\mathrm{o}}-\mathrm{F}_{\mathrm{c}}$ electron density contoured at $2.5 \sigma$, showing contact between $16 \mathrm{~S}$ rRNA (cyan, left), and $23 \mathrm{~S}$ rRNA (gray, right), around intersubunit bridge B3. (B) Electron density map for RF3. Stereo representation of unbiased 3.3 A resolution $\mathrm{F}_{\mathrm{o}}-\mathrm{F}_{\mathrm{c}}$ electron density for release factor RF3, contoured at $2.4 \sigma$. 

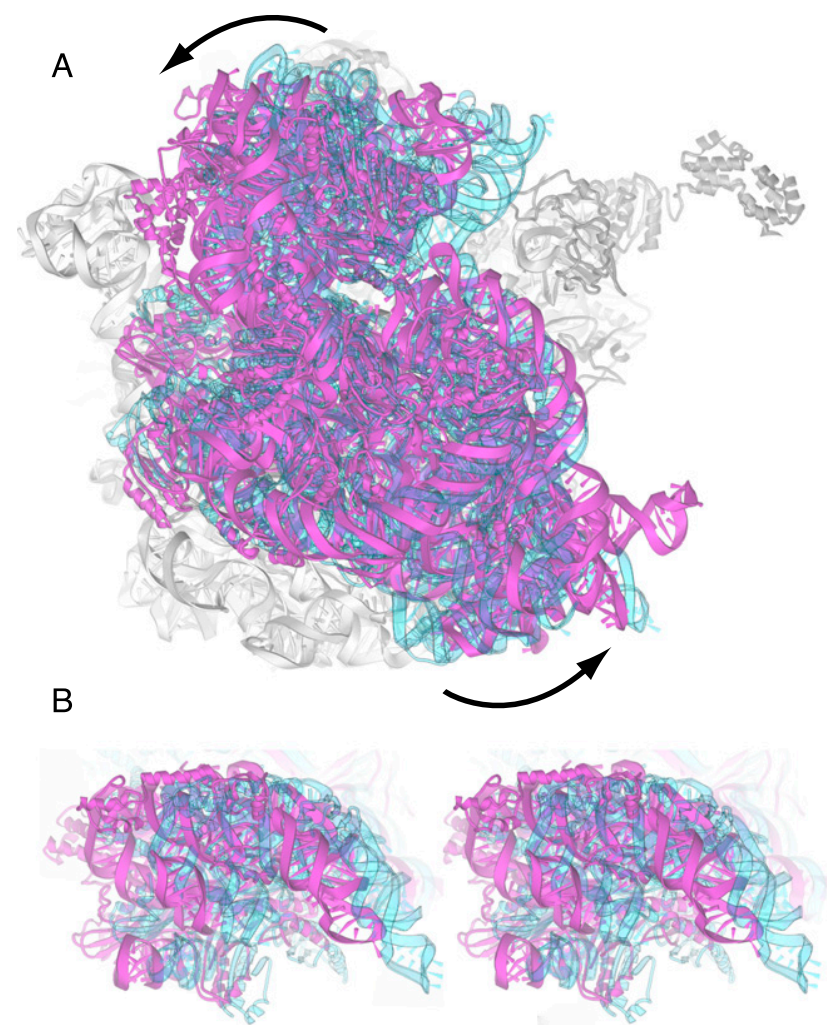

FIGURE 2. Conformational changes in the ribosome in the RF3.GDPNP complex. (A) $7^{\circ}$ counter-clockwise rotation of the $30 \mathrm{~S}$ subunit (foreground) in the RF3 complex, as viewed from the solvent surface of the $30 \mathrm{~S}$ subunit, relative to the classical-state RF2 complex (Korostelev et al. 2008a). The 50S subunit (gray) is in the background. (B) Stereo view showing $14^{\circ}$ counter-clockwise rotation of the head domain of the $30 \mathrm{~S}$ subunit, as viewed from the top of the subunit. The subunit interface is at the top of the figure. $16 \mathrm{~S}$ rRNA and $30 \mathrm{~S}$ proteins are colored magenta (RF3 complex) and cyan (RF2 complex).

at intersubunit bridge B3. A subtler counter rotation of the platform of the $30 \mathrm{~S}$ subunit helps to preserve the intersubunit contacts in bridge B4 (see below). Rotation of the $30 \mathrm{~S}$ subunit body is similar to that observed in cryo-EM reconstructions of EF-G and RF3 complexes (Frank and Agrawal 2000; Klaholz et al. 2004; Gao et al. 2007) and for the recent crystal structure of a complex containing tRNA trapped in the P/E hybrid state in the presence of RRF (Dunkle et al. 2011). In the RF3 complex, there is also a dramatic $14^{\circ}$ counter-clockwise rotation (when viewed from above) of the head of the $30 \mathrm{~S}$ subunit (Fig. 2B). Rotation of the head opens the previously noted constriction between the 30S P and E sites (Schuwirth et al. 2005) and results in movement of P-site elements in the head into a position juxtaposed with E-site elements of the $30 \mathrm{~S}$ body (discussed below). Combined rotation of the $30 \mathrm{~S}$ subunit body and head results in overall movements as great as $35 \AA$ between equivalent positions in the classical and RF3-bound rotated states.

Intersubunit and head rotation result in rearrangement or disruption of many of the dozen bridges that connect the $30 \mathrm{~S}$ and 50S subunits (Fig. 3; Supplemental Table S2; Yusupov et al. 2001; Schuwirth et al. 2005). Several of the most central bridges are preserved by flexing of local structural elements, while the peripheral bridges are rearranged or completely disrupted and replaced by new bridges in the rotated structure. For example, both bridges joining the head of the $30 \mathrm{~S}$ subunit to the top of the 50S subunit (bridges B1a and B1b) are disrupted; in their place, a new bridge, $\mathrm{R} 1 \mathrm{~b}$, is formed between $50 \mathrm{~S}$ protein $\mathrm{L} 5$ and $30 \mathrm{~S}$ proteins S13 and S19, resulting in displacement of the L5 contact to the $30 \mathrm{~S}$ head by a distance of $>30 \AA$ (Fig. 3C,D). Changes in bridges involving the $30 \mathrm{~S}$ subunit body are similar, but not identical, to those reported for the RRF hybrid-state structure (Dunkle et al. 2011). The contacts forming bridge B2a, which connects helices 44 and 45 of $16 \mathrm{~S}$ rRNA to helix 69 of $23 \mathrm{~S}$ rRNA and contains the highest density of intersubunit interactions, are almost completely preserved between the classical and rotated states. This is accomplished by rotation of helix 69 to match the movement of the $30 \mathrm{~S}$ subunit (Supplemental Fig. S4A). In contrast to the RRF hybrid-state structure, where there is some rearrangement of the secondary structure of helix 69 , in the RF3 complex the terminal base pair (C1925-G1929) is preserved, and the conserved U1926 remains in its intercalated position (Supplemental Fig. S4B). Helix 34 of $23 \mathrm{~S}$ rRNA, which contacts $30 \mathrm{~S}$ protein S15 to form Bridge B4 (Culver et al. 1999), bends in its internal loop around positions 705/ 726 , resulting in a $6 \AA$ displacement at its apical loop to maintain interaction with S15 in the RF3-bound rotated state (Supplemental Fig. S5A). Bridge B7a, formed by tertiary contacts between A702 of 16S rRNA and G1846 and A1848 of $23 \mathrm{~S}$ rRNA, is disrupted in the RF3 structure and replaced by bridge R7a, in which A702 is displaced by 13 $\AA$ to hydrogen bond with phosphate 1847 (Supplemental Fig. S5B).

\section{Binding of RF3 to the ribosome}

RF3 binds to the ribosome at the subunit interface, bridging the $30 \mathrm{~S}$ and $50 \mathrm{~S}$ subunits in a position that overlaps with those of EF-G and EF-Tu (Fig. 4A; Supplemental Fig. S6). Like the other GTPase factors, RF3 contacts the 50S subunit surface at the sarcin-ricin loop (SRL) (helix 95) of $23 \mathrm{~S}$ rRNA. However, domain I (the G domain) of RF3 binds to the SRL of the 50S subunit in an orientation that differs markedly from that observed for EF-Tu and EF-G (Gao et al. 2009; Schmeing et al. 2009; Voorhees et al. 2010), as discussed below. In contrast to EF-Tu and EF-G, the G domain of RF3 contacts protein L6 and not the L11 stalk (Fig. 4B). RF3 is well ordered, allowing many individual side chains to be resolved in an unbiased electron density map (Fig. 1B). Binding to the ribosome results in extensive structural rearrangement of RF3 relative to its free GDP form, both in the relative orientations of its three domains and in the structure within the domains themselves. Relative to the 
Classical

A

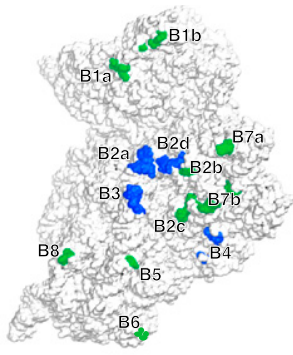

B

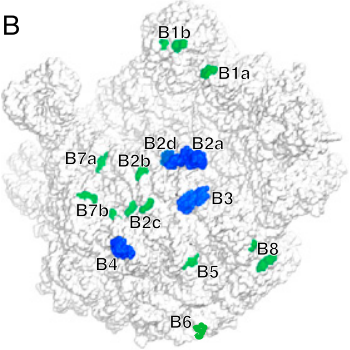

C

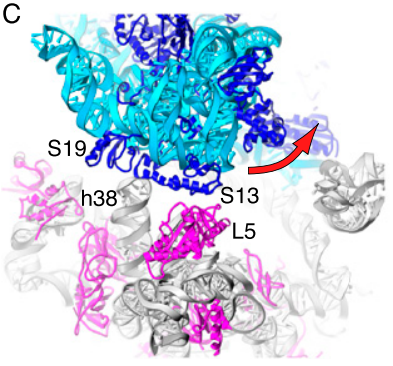

Rotated (RF3)
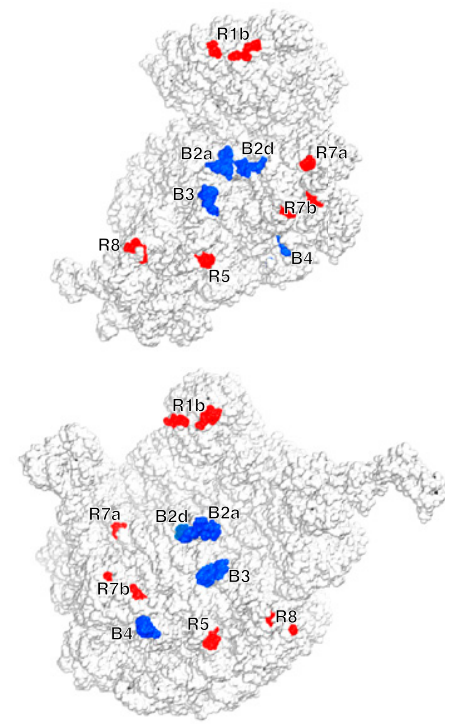

D

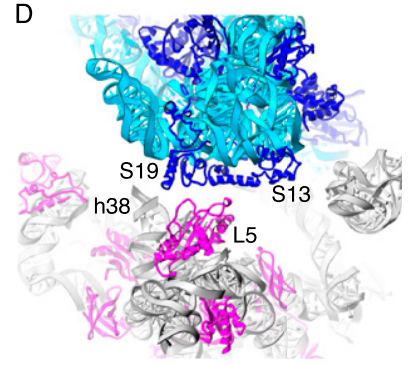

FIGURE 3. Rearrangement of intersubunit bridges. $(A, B)$ Molecular surface representations of $(A) 30 \mathrm{~S}$ subunits and $(B) 50 \mathrm{~S}$ subunits showing intersubunit bridge contacts of the classical-state RF2 70S ribosome complex (left) (Korostelev et al. 2008a) and the rotated RF3 $70 S$ complex (right). Bridge contacts are colored according to whether they are maintained (blue), disrupted (green), or newly formed (red) in the rotated state. Classical-state bridges are numbered according to Yusupov et al. (2001). (C,D) Disruption and reformation of intersubunit bridges involving the head of the $30 \mathrm{~S}$ subunit. (C) In the classical-state RF2 complex, bridge B1a is formed between protein $\mathrm{S} 13$ and helix 38 of $23 \mathrm{~S}$ rRNA, and B1b between S13 and L5. (D) In the RF3 complex, a large-scale counter-clockwise rotation of the $30 \mathrm{~S}$ head results in disruption of bridges $\mathrm{B} 1 \mathrm{a}$ and $\mathrm{B} 1 \mathrm{~b}$; bridge $\mathrm{R} 1 \mathrm{~b}$ is formed between proteins S13 and S19 from the 30S subunit and L5 from the $50 \mathrm{~S}$ subunit, involving a $34 \AA$ displacement of the intersubunit contacts.

G domain, domain II undergoes a $7^{\circ}$ rotation and domain III is rotated by $55^{\circ}$, enabling contacts with the two ribosomal subunits that are responsible for stabilizing intersubunit rotation. The large-scale movement of domain III, which was already apparent from cryo-EM reconstruction (Gao et al. 2007), results in displacements of up to $35 \AA$ (Fig. 5A,B).

Many additional differences are seen in the crystal structure of ribosome-bound RF3, most notably conformational changes within domains I and II. In domain I, residues 39-69, which contain switch loop I, a functionally important feature that is conserved among $G$ proteins (Wittinghofer and Vetter 2011), and disordered in all previous structures of RF3 and EF-G, become ordered in the RF3.GDPNP.ribosome complex, completing the enclosure that surrounds GDPNP within its binding site (Fig. 6A). As discussed below, ordering of the region upstream of switch loop I results in formation of a unique contact with the SRL around positions $2655 / 2664$, which contributes to the unusual orientation of the G domain on the SRL. Residues 91-95 in the rearranged switch loop II form part of the $\gamma$-phosphate-proximal end of the GDPNP binding site and additionally create an interaction with positions 442-443, potentially stabilizing the rotation of domain III. On the $30 \mathrm{~S}$ subunit, domains II and III of RF3 form a complementary surface that contacts protein S12 and 16S rRNA helices h5 and h15 (Fig. 4C). The universally conserved His311 in domain II contacts the surface of $16 \mathrm{~S}$ rRNA at a site centered on the universally conserved A55-U368 tertiary base pair, which connects h5 and h15. Domain III interacts with the lower edge of protein S12 and makes salt bridges to the adjacent phosphate at position 359 in 16S rRNA.

GDPNP is held by extensive contacts with backbone and side-chain groups of the conserved P loop, switch 1, and NKXD motifs of RF3 (Fig. 6A). The triphosphate and ribose of GDPNP are buried in a narrow cavity inside domain I of RF3, while its guanine moiety is exposed to the backbone of the sarcin loop of $23 \mathrm{~S}$ rRNA, where phosphate 2656 forms a hydrogen bond with its 2 -amino group. The guanosine is further positioned in its RF3-binding pocket by H-bonds between its N1 and N2 positions with Asp145,
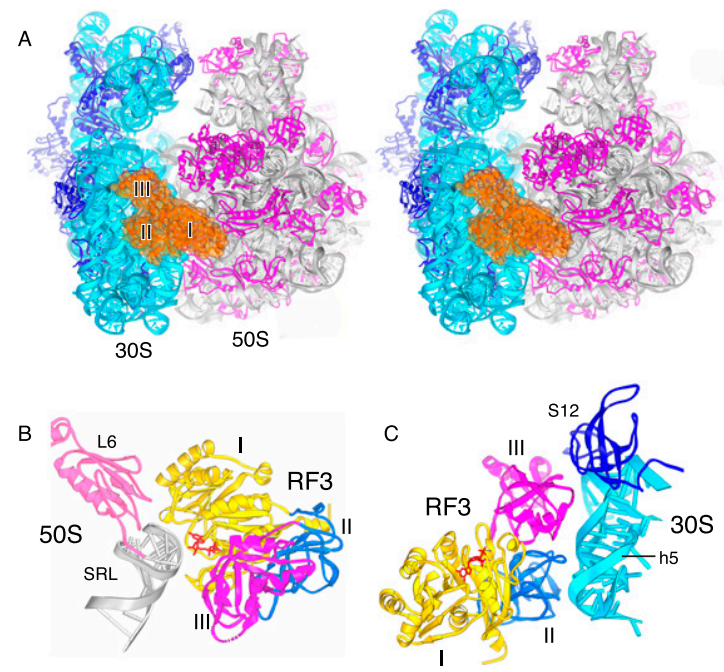

FIGURE 4. Binding of RF3 to the 70S ribosome. (A) Stereo view of RF3 (orange) bound at the entrance to the interface cavity of the $70 \mathrm{~S}$ ribosome. (B) RF3 contacts viewed from inside the interface cavity. Domain I (the G domain; yellow) of RF3 interacts with the sarcinricin loop (SRL) of 23S rRNA (gray) and with protein L6 (light magenta). (C) View from inside the interface cavity, showing contacts between domains II (blue) and III (magenta) of RF3 with helix 5 of $16 \mathrm{~S}$ rRNA (cyan) and protein S12 (dark blue). 
A
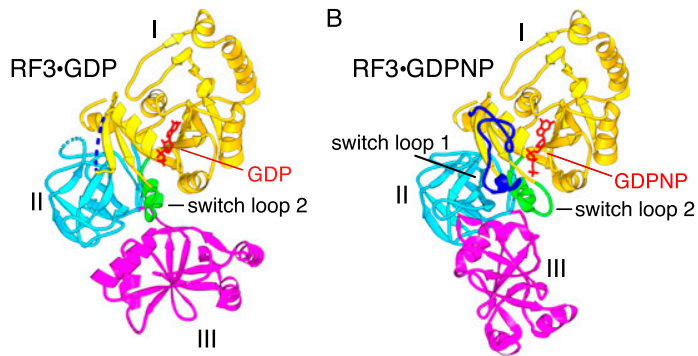

C

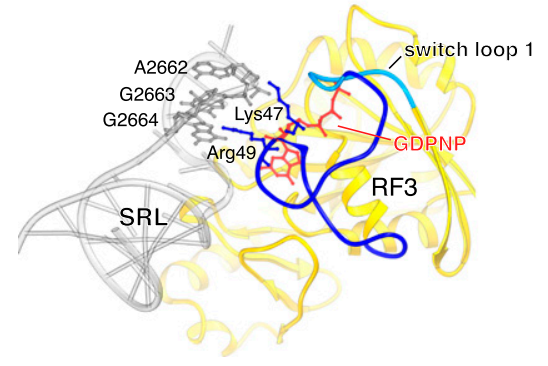

FIGURE 5. Conformational rearrangements in RF3. $(A, B)$ Comparison of crystal structures of free RF3.GDP (A) (Gao et al. 2007) and ribosome-bound RF3.GDPNP (B). A large-scale rotational movement of domain III (magenta) and smaller movements in domains I (yellow) and II (cyan) can be seen. Disordered segments in RF3.GDP are shown as dotted lines. Rearranged segments in RF3.GDPNP containing switch loops I and II are shown in blue and green, respectively. GDP and GDPNP are shown in red. $(C)$ Ordering of residues 39-69 and repositioning of residues 70-73 of RF3 (including the switch loop 1 residues 64-72) creates a contact between the G domain of RF1 and the SRL of $23 \mathrm{~S}$ rRNA. Residues 39-63 are shown in dark blue, the switch loop in cyan, and the rest of RF3 in yellow.

and O6 with Asn142; packing against the Lys143 side chain and of its ribose against Val46; and an H-bond between the backbone oxygen of Val46 and the ribose $3^{\prime}-\mathrm{OH}$ group. The $\alpha$ phosphate makes $\mathrm{H}$-bonds to the side chain and backbone of Thr28. The $\mathrm{F}_{\mathrm{o}}-\mathrm{F}_{\mathrm{c}}$ difference electron density for GDPNP shows a peak positioned next to the scissile $\beta-\gamma$ phosphate linkage (Fig. 6B). This density likely corresponds to a bound magnesium ion seen in many $\mathrm{G}$ proteins (Wittinghofer and Vetter 2011), which coordinates with the $\beta$ and $\gamma$ phosphates and with the side-chain hydroxyls of Thr27 and Ser69. The $\beta$ phosphate is also held by $\mathrm{H}$-bonds to the backbone amide groups of Ala24, Gly25, and Thr27, and the $\gamma$ phosphate by H-bonds with backbone NH groups of Asp23 and Gly91. His92, which has been proposed to act as a general base in the GTPase reaction (Voorhees et al. 2010), is oriented away from the $\gamma$-phosphate (Fig. 6C).

\section{Binding of viomycin in the RF3 complex}

The RF3.70S ribosome complex was crystallized both in the presence and absence of the antibiotic viomycin, a translocation inhibitor whose inclusion improved the diffraction properties of the crystals (Supplemental Table S1). An $F_{o}-F_{c}$ difference electron density map shows density for viomycin in the decoding site of the $30 \mathrm{~S}$ subunit (Supplemental Fig. S7), at a location essentially identical to that recently identified by Steitz and coworkers for binding of viomycin to classical-state Thermus thermophilus $70 \mathrm{~S}$ ribosomes (Stanley et al. 2010). Viomycin is bound to a site that is normally occupied by stacking of bases A1492 and A1493 at the top of helix 44 . Both bases are flipped out in our structure (Supplemental Fig. S7), as in the Stanley et al.

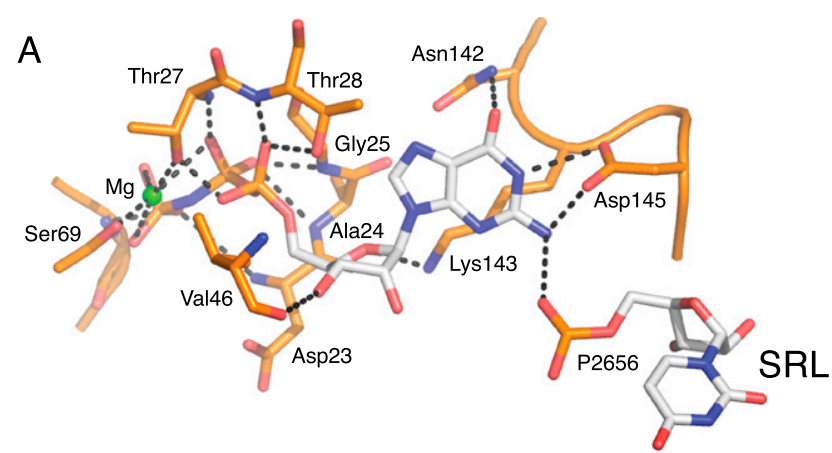

B
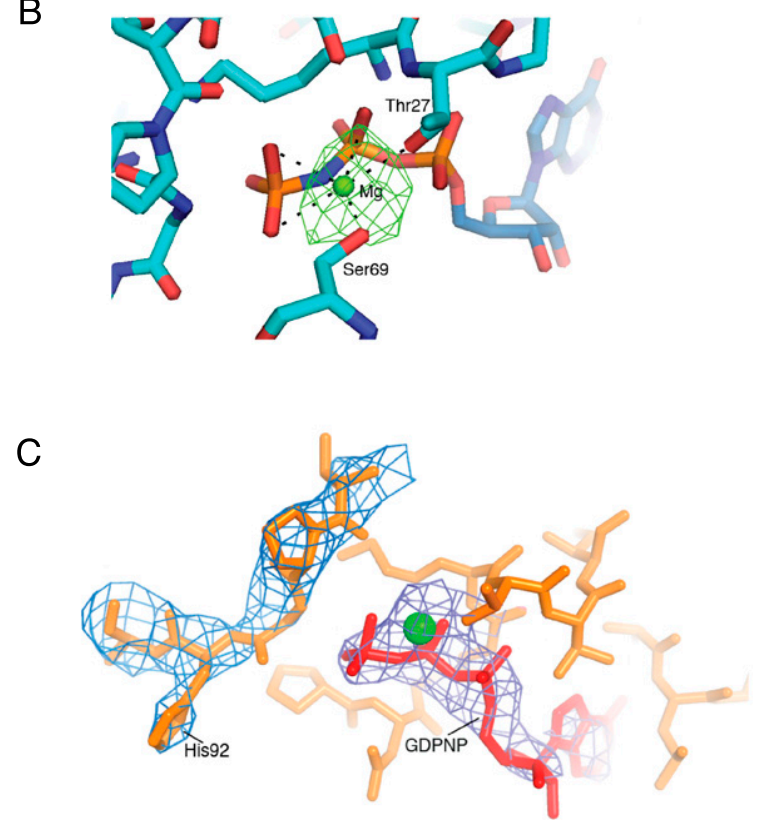

FIGURE 6. Interactions in the GTP binding site of RF3. (A) An intricate network of $\mathrm{H}$-bonds is formed between the base, ribose, and phosphate groups of GDPNP and domain I of RF3, including elements of switch I (residues 64-72), P loop (residues 21-28), NKXD motif (residues 142-145), and phosphate 2656 of the SRL of $23 \mathrm{~S}$ rRNA. A Mg atom (green) is coordinated by Thr27, Ser91, and the $\beta$ and $\gamma$ phosphates of GDPNP (see Supplemental Fig. S9). (B) Difference electron density showing $\mathrm{Mg}$ bound to GDPNP. An $\mathrm{F}_{\mathrm{o}}-\mathrm{F}_{\mathrm{c}}$ difference map was calculated using the complete RF3.GDPNP.70S ribosome model, shown here contoured at $4.5 \sigma$. The $\mathrm{Mg}$ ion (green) is coordinated with the $\beta$ and $\gamma$-phosphate oxygens of GDPNP and with the side-chain hydroxyls of Thr27 and Ser 69. (C) His92 of RF3 is positioned at a distance of $8 \AA$ from the $\gamma$ phosphate of GDPNP. The $2 \mathrm{~F}_{\mathrm{o}}-\mathrm{F}_{\mathrm{c}}$ electron density map is shown around His92 and GDPNP, contoured at $1.3 \sigma$ and $2.3 \sigma$, respectively. 
(2010) structure, similar to the conformations induced by binding of paromomycin (Ogle et al. 2001), which binds to a site that overlaps with that of viomycin. Although viomycin itself has been shown to stabilize intersubunit rotation in solution (Ermolenko et al. 2007b), binding of viomycin to the classical-state ribosome suggests that its effects on intersubunit rotation in solution can be overcome by forces generated during formation of the crystal lattice. It is not obvious from the location of viomycin in the $30 \mathrm{~S}$ decoding site how it influences intersubunit rotation. In any case, the rotational state that we observe for the RF3 complex is formed independently of the presence of viomycin; identical intersubunit and head rotations are observed in a lower-resolution $(3.8 \AA$ ) structure obtained from crystals grown from an otherwise identical RF3 complex formed in the absence of viomycin (Supplemental Fig. S8; Supplemental Table S1). Apart from the flipping of bases A1492 and A1493 of 16S rRNA, and rearrangement of the nearby A1913 of $23 \mathrm{~S}$ rRNA, no major viomycin-dependent structural differences were detected (overall RMSD = $0.76 \AA$ ), within the limits of the resolution of the two structures (Supplemental Fig. S10).

\section{DISCUSSION}

\section{Release of RF1 and RF2 by RF3}

Our structure provides a structural basis for understanding how RF3 catalyzes dissociation of release factors RF1 and RF2 from the ribosome following termination of protein synthesis (Goldstein and Caskey 1970; Freistroffer et al. 1997). Termination complexes contain RF1 or RF2 bound to the ribosome in its classical, nonrotated state (Rawat et al. 2003, 2006; Korostelev et al. 2008a, 2010; Laurberg et al. 2008; Weixlbaumer et al. 2008). It has been shown that deacylation of peptidyl-tRNA must occur prior to removal of RF1/RF2 by RF3 (Zavialov et al. 2002), most likely to allow $\mathrm{P} / \mathrm{E}$ hybrid-state formation of the deacylated tRNA and, therefore, intersubunit rotation. With RF3GDPNP bound, the resulting rotated state of the ribosome creates clash between domain IV of RF2 (positions 330-340) and the head of the 30S subunit (16S rRNA positions 12081210), and between domain I of RF2 (positions 45-50) and the L11 stalk (23S rRNA positions 1067-8). Thus, both of the major rotational changes induced by RF3 - of the $30 \mathrm{~S}$ subunit head and body-would contribute to disruption of interactions between RF2 and the ribosome. GTP hydrolysis would then lead to release of RF3.GDP, caused by the predicted disruption of contact between domain III of RF3.GDP and the $30 \mathrm{~S}$ subunit in the rotated state.

Although the structure of free RF3-GTP is not known, if it resembles that of ribosome-bound RF3-GDPNP, steric clash between domain III of RF3 and protein S12 would interfere with binding of RF3.GTP to the nonrotated termination complex. Ehrenberg and coworkers have proposed that RF3-GDP first binds the termination complex, followed by ribosome-facilitated nucleotide exchange, in which GDP is replaced by GTP (Zavialov et al. 2001). Indeed, when RF3.GDP is docked on the SRL of the nonrotated RF2 termination complex by aligning its $G$ domain with the position of the G domain of RF3.GDPNP in our structure, the steric clash predicted for RF3-GDPNP with the nonrotated ribosome is relieved; in addition, this modeling predicts formation of an interaction between domain III of RF3 and domain I of RF2 (Supplemental Fig. S9), suggesting a potential functional role for domain I of the type I release factors. However, the fact that RF3.GDP does not bind stably to the termination complex (Pel et al. 1998; Supplemental Fig. S10) is inconsistent with this scenario in its simplest form. An alternative possibility is that the termination complex exists in equilibrium between its rotated and nonrotated states, and RF3.GTP binds to and traps the complex in its rotated form. Further experiments will be needed to resolve these possibilities.

\section{GTP hydrolysis}

Based on the crystal structure of an EF-Tu-GDPCP-ribosome complex, Ramakrishnan and coworkers proposed a universal mechanism for GTPase activation of translational GTPases by the ribosome (Voorhees et al. 2010). A conserved histidine (His84 in EF-Tu) that has been implicated in catalysis of GTP hydrolysis (Cool and Parmeggiani 1991), interacts with the phosphate of SRL nucleotide A2662, thus orienting it toward a water positioned next to the $\gamma$ phosphate of GDPCP. Voorhees et al. (2010) propose that this histidine plays a crucial catalytic role, acting as a general base to abstract a proton from the water for in-line attack on the $\gamma$ phosphate of GTP, and predict that its positioning by A2662 of the SRL is a universal mechanism for GTPase activation on the ribosome.

Our structure of RF3.GDPNP bound to the ribosome is inconsistent with the universal mechanism proposed by Voorhees et al (2010). The corresponding histidine residue in RF3, His92, is $8 \AA$ from the $\gamma$-phosphate of GDPNP (Fig. $6 \mathrm{C})$, ruling out its participation as a general base. The contribution of a general base to catalysis by EF-Tu and other $G$ proteins in this way is the subject of ongoing discussion. Liljas et al. (2011) note that in numerous previously published structures of translational GTPases, this histidine is seen in many different positions, but rarely at the water molecule adjacent to the $\gamma$-phosphate, and cite studies implicating the $\gamma$-phosphate itself as a general base. In an analysis of the mechanism of the related Ras GTPase, Herschlag and coworkers (Maegley et al. 1996; Lassila et al. 2011) show that for a dissociative transition state, there would be little advantage for removal of a proton from the attacking water. Instead, they point out that the atom undergoing the largest change in charge during formation of the transition state is the $\beta-\gamma$ bridge oxygen, and thus 
stabilization of its developing negative charge would make a more substantial contribution to catalysis. Finally, EF-G-2, which carries out ribosome-stimulated GTP hydrolysis (Connell et al. 2007), contains a tyrosine rather than a histidine residue at the corresponding position of its $\mathrm{P}$ loop, which is incompatible with the universality of the proposed mechanism.

In contrast to the EF-Tu complex (Voorhees et al. 2010), SRL nucleotide A2662 does not contact GDPNP or RF3. The sole interaction between the SRL and GDPNP is between phosphate 2656 and the 2-amino group of the guanine of GDPNP. We suggest that, in the case of RF3, ribosome-dependent GTP hydrolysis is an indirect result of the ordering of RF3 when it binds to the ribosome. In all previous structures of RF3 and EF-G, including the structure of the EF-G-ribosome complex (Gao et al. 2009) the region of the $G$ domain corresponding to residues 39-69 are disordered; in the RF3-ribosome structure described here, this region becomes ordered (Fig. 5C; Supplemental Fig. S11), which results in positioning of critical elements of the GTPase active site. Upstream of switch loop 1, interactions between Lys47 and Arg49 and SRL nucleotides 2664 and 2663, respectively (Fig. 5C; Supplemental Fig. S11), anchor Val46 in the active site and contribute to the conformational change in switch loop 1 that includes positioning of Ser69 to coordinate the critical $\mathrm{Mg}$ ion at the $\beta$ - $\gamma$-phosphate linkage.

\section{Possible implications for the mechanism of translocation}

The $7^{\circ}$ rotation of the $30 \mathrm{~S}$ subunit body in our structure is similar to that observed for the recent crystal structure of a hybrid-state complex formed with RRF (Dunkle et al. 2011) and for cryo-EM reconstructions of EF-G- and RF3containing complexes (Frank and Agrawal 2000; Klaholz et al. 2004; Ratje et al. 2010). The pronounced $14^{\circ}$ rotation of the $30 \mathrm{~S}$ head more closely resembles the conformation of the $30 \mathrm{~S}$ subunit in cryo-EM structures of a newly identified state ("substate II") observed in cryo-EM reconstructions of a $70 \mathrm{~S}$ ribosome.EF-G complex (Ratje et al. 2010) and of an 80 S ribosome-eEF2 complex (Spahn et al. 2004), and in a crystal structure of the vacant yeast $80 \mathrm{~S}$ ribosome (BenShem et al. 2010). In the RF3 complex, the positions of the tRNA-binding elements of the 30S subunit head, including G966, G1338, and A1339, which form the main contacts between the ribosome and the ASL of P-site tRNA (Berk et al. 2006; Korostelev et al. 2006; Selmer et al. 2006), are dramatically displaced. Specifically, G1338, which contacts the minor groove of the anticodon stem of P-site tRNA in the classical state, moves by $23 \AA$ toward the E site from its location in the nonrotated ribosome, virtually identical to the distance traversed by the ASL during translocation from the $30 \mathrm{~S} \mathrm{P}$ site to the $\mathrm{E}$ site. In the same rotational movement, the gap between the head and platform, which in the classical state is too narrow to allow passage of the ASL between the $\mathrm{P}$ and $\mathrm{E}$ sites (Schuwirth et al. 2005), is widened from 15 to $22 \AA$, sufficient to permit translocation of the ASL. Figure 7 illustrates how the positions of the tRNAs would change between the classical and rotated RF3-bound states with their ASLs following the movement of the head of the 30S subunit, as suggested by cryo-EM studies (Fischer et al. 2010; Ratje et al. 2010). Thus, a combination of $30 \mathrm{~S}$ body and head rotations similar to those observed here is sufficient to allow for the repositioning of the tRNA ASLs that is required for translocation.

Previous crystal structures of EF-G.GDP and EF-Tu-GDP or EF-Tu-GDPCP bound to the ribosome showed a nearly identical binding orientation of their $\mathrm{G}$ domains to the SRL of 23S rRNA (Gao et al. 2009; Schmeing et al. 2009; Voorhees et al. 2010). However, orientation of the G domain of RF3.GDPNP differs from that of the other two factors. This is illustrated in Figure $8 \mathrm{~A}$, in which the structures of the respective $\mathrm{G}$ domains of EF-Tu, EF-G, and RF3 are aligned by a least-squares fit. Although the orientation of the SRL relative to the $\mathrm{G}$ domain is virtually identical for EF-Tu and EF-G, that of RF3 is rotated by $\sim 45^{\circ}$ from that of the other factors. Since the orientation of the SRL itself in the 50S subunit is unchanged between the different factor complexes within experimental error, this illustrates the distinctly different orientation of the G domain of RF3.

It is not known whether the other GTPase factors can bind to the SRL in the RF3 orientation; however, it seems unlikely that this orientation is unique to RF3, given the conservation and structural similarities between the $\mathrm{G}$ domains of EF-G and RF3 (Fig. 8B). This possibility is of some interest, because the orientation of EF-G on the $70 \mathrm{~S}$ ribosome, as seen in all but one cryo-EM reconstructions (Frank and Agrawal 2000; Stark et al. 2000; Valle et al. 2003; Ratje et al. 2010) and in the single crystal structure of an EF-G.70S ribosome complex (Gao et al. 2009), places domain IV of EF-G in the intersubunit cavity in a position that creates

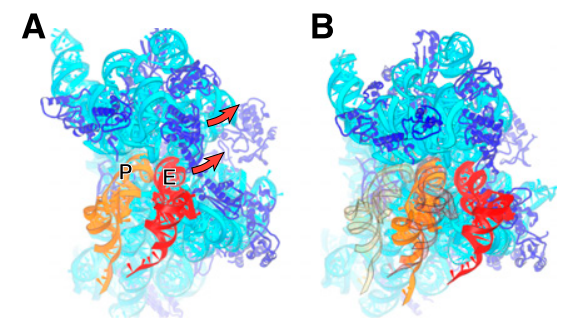

FIGURE 7. Geometry of head rotation and tRNA positioning in the 30 S subunit. P-site ASL contacts in the 30 s subunit head are displaced by $23 \AA$ in the RF3 complex, relative to their position in the classicalstate RF2 complex. Docking of P-site (orange) and E-site (red) tRNAs on the $(A)$ classical-state RF2 and $(B)$ rotated RF3 structures illustrates that the combined $30 \mathrm{~S}$ head and body rotations seen in the RF3 structure are sufficient to translocate an ASL from the 30S P site to the $\mathrm{E}$ site. The views in $A$ and $B$ are shown in exactly the same orientation relative to the $50 \mathrm{~S}$ subunit. In $B$, the initial positions of the P-and E-site tRNAs as in $A$ are shown in transparent orange and red, respectively. 
A
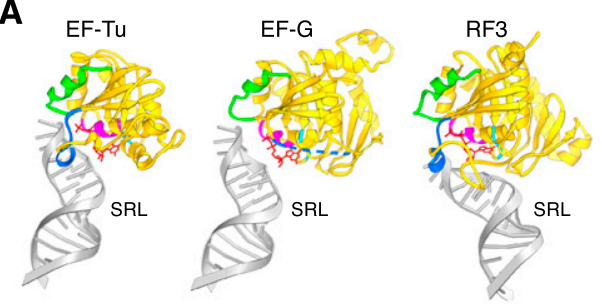

B
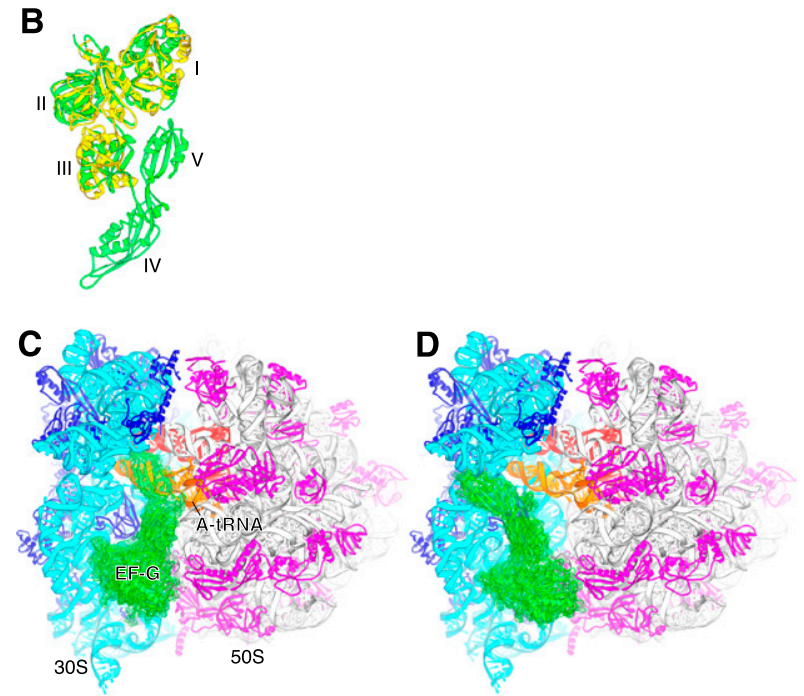

FIGURE 8. Implications of the orientation of RF3 domain I for EF-G binding. (A) Orientations of domain I of EF-Tu (Voorhees et al. 2010), EF-G (Gao et al. 2009), and RF3 (this work) relative to the SRL of 23S rRNA. The domains were aligned in three dimensions by virtue of their conserved structural elements. The conserved functional elements of the respective factors are indicated: switch 1 (blue); switch 2 (green); P loop (magenta); NKXD motif (cyan). The G nucleotides are shown in red. The orientation of the SRL in in the RF3 complex is rotated by $\sim 45^{\circ}$ relative to those of the other factors. $(B)$ Three-dimensional alignment of Domains I, II, and III of RF3.GDPNP (yellow) and EF-G (green) (Gao et al. 2009) show clear structural homology. (C) Observed orientation of EF-G (green) bound to the classical-state $70 \mathrm{~S}$ ribosome.EF-G complex (Gao et al. 2009), in which an A-site tRNA has been docked in the A site; note the steric clash with A-site tRNA. (D) Orientation of EF-G in the classical-state ribosome with its domain I docked on the 50S subunit in the same orientation as that of RF3.GDPNP. Note the absence of steric clash with A-site tRNA or the ribosome.

severe clash with a tRNA bound to the A site (Fig. 8C). Since the biological role of EF-G requires that it acts on ribosomes containing tRNAs bound to both the $\mathrm{A}$ and $\mathrm{P}$ sites, it must bind to the ribosome initially in a different orientation. Alignment of the G domain of EF-G with that of RF3 results in a remarkable repositioning of EF-G, in which domain IV avoids all contact with A-site tRNA, and instead transversely spans the entrance to the interface cavity, where its tip contacts the top of the shoulder at the outer edge of the $30 \mathrm{~S}$ subunit (Fig. 8D). This orientation of EF-G may be similar to that seen in an earlier cryo-EM reconstruction of EF-G.GTP trapped in the presence of thiostrepton (Stark et al. 2000). In our structure, residues 45-53 of RF3 form a loop that makes an additional contact to the SRL that may stabilize its orientation. The corresponding region of EF-G is disordered in the EF-G.GDP.70S ribosome-fusidic acid complex; thus, it is possible that it rearranges during initial binding of EF-G to form a similar interaction that stabilizes an RF3-like orientation. Resolution of these and the many other unanswered questions concerning ribosome structural dynamics will depend on elucidation of the structures of additional functional complexes, and crucially, on critical tests of mechanistic models.

After completion of this work, the crystal structure of $E$. coli RF3 bound to T. thermophilus ribosomes was reported by Ramakrishnan and coworkers (Jin et al. 2011). Their structure differs from the one presented here in several respects. The rotation of the $30 \mathrm{~S}$ subunit body, smaller rotation of the $30 \mathrm{~S}$ subunit head, and presence of a P/E hybrid-state tRNA all very closely resemble those observed by Cate and coworkers for E. coli hybrid-state ribosomes complexed with RRF (Dunkle et al. 2011). Few details of the interactions between RF3 and the ribosome or the structural rearrangements in RF3 are reported, including structures for the previously disordered loops, most likely because of lower resolution and low occupancy of RF3.GDPCP for their complex. The greater degree of head rotation seen in our structure and in the subpopulation reported by Spahn and coworkers (Ratje et al. 2010) suggests that this conformation may represent an intermediate state that is disfavored in the presence of a bound tRNA.

\section{MATERIALS AND METHODS}

\section{Preparation of ribosome-RF3 complex}

Tight-couple $70 S$ ribosomes were prepared from E. coli strain CSH142/L9 $\Delta \mathrm{K}$ (Lieberman et al. 2000), which lacks 50S ribosomal protein L9. Typically, $2 \mathrm{~L}$ of cells grown to mid-log at $37^{\circ} \mathrm{C}$ was spun down, resuspended in buffer A $(20 \mathrm{mM}$ Tris- $\mathrm{Cl}$ at $\mathrm{pH} 7.0$, $100 \mathrm{mM} \mathrm{NH}_{4} \mathrm{Cl}, 10.5 \mathrm{mM} \mathrm{MgCl}_{2}, 0.5 \mathrm{mM}$ EDTA, and $5 \mathrm{mM}$ $\beta \mathrm{ME})$, lysed, and pelleted through two $10-\mathrm{mL}$ cushions containing 1.1 M sucrose and high-salt buffer A $(20 \mathrm{mM}$ Tris- $\mathrm{Cl}$ at $\mathrm{pH}$ 7.0, $500 \mathrm{mM} \mathrm{NH}_{4} \mathrm{Cl}, 10.5 \mathrm{mM} \mathrm{MgCl}_{2}, 0.5 \mathrm{mM}$ EDTA, and $5 \mathrm{mM}$ $\beta M E)$, in a Beckman Ti60 rotor at $39,000 \mathrm{rpm}$ for $20 \mathrm{~h}$ at $4^{\circ} \mathrm{C}$. Each pellet was resuspended in $25 \mathrm{~mL}$ of high-salt buffer $\mathrm{A}$, then pelleted in a Ti60 rotor at 55,000 rpm for $2 \mathrm{~h}$ at $4^{\circ} \mathrm{C}$. This was repeated once. The salt-washed ribosome pellets were dissolved in a total volume of $2 \mathrm{~mL}$ of buffer A and layered onto six $38-\mathrm{mL}$ $10 \%-35 \%$ sucrose gradients containing $20 \mathrm{mM}$ Tris- $\mathrm{Cl}$ ( $\mathrm{pH} 7.0$ ), $100 \mathrm{mM} \mathrm{NH}_{4} \mathrm{Cl}, 6 \mathrm{mM} \mathrm{MgCl}_{2}$, and $5 \mathrm{mM} \beta \mathrm{ME}$. Gradients were centrifuged in a Beckman SW28 rotor at 19,000 rpm for $16 \mathrm{~h}$ at $4^{\circ} \mathrm{C}$. The $70 \mathrm{~S}$ ribosome peak was collected, and the $\mathrm{MgCl}_{2}$ concentration was increased to $10 \mathrm{mM}$ before pelleting in a Beckman Ti45 rotor at $36,000 \mathrm{rpm}$ for $22 \mathrm{~h}$ at $4^{\circ} \mathrm{C}$. The ribosome pellet was dissolved in $100 \mu \mathrm{L}$ of buffer $\mathrm{A}$, aliquoted, quick-frozen in liquid $\mathrm{N}_{2}$, and stored at $-80^{\circ} \mathrm{C}$.

E. coli RF3 was amplified from MRE600 genomic DNA using primers 5 '-TTTCCATCCCATATGACGTTGTCTCCTTATTTGC and $5^{\prime}$-CCTATACCGGATCCTTAATGCTCGCGGGTCTGGTGG, then ligated into the Nde1/BamHI sites of pET21b (Novagen). 
Five additional His residues were added to the C-terminal His by site-directed mutagenesis (Kunkel 1985), to generate pRF3-C-6His. RF3-C-6His protein was expressed in strain BLR(DE3) by induction with $1 \mathrm{mM}$ IPTG for $3 \mathrm{~h}$. The cell pellet from $1 \mathrm{~L}$ was resuspended in $10 \mathrm{~mL}$ of $25 \mathrm{mM}$ Tris- $\mathrm{Cl}$ (pH 7.5), $50 \mathrm{mM} \mathrm{KCl}, 15$ $\mathrm{mM}$ imidazole, $15 \%$ glycerol, and $5 \mathrm{mM} \beta \mathrm{ME}$; lysed through a French press at $18,000 \mathrm{psi}$; then centrifuged at $10,000 \mathrm{rpm}$ for 20 min in a Beckman JA20 rotor at $4^{\circ} \mathrm{C}$. The supernatant was incubated with $2 \mathrm{~mL}$ of Ni-NTA agarose resin (QIAGEN) for $1 \mathrm{~h}$ at $4^{\circ} \mathrm{C}$. The resin was washed with $40 \mathrm{~mL}$ of the same buffer containing an additional $500 \mathrm{mM} \mathrm{KCl}$. RF3 was eluted with $6 \mathrm{~mL}$ of 50 $\mathrm{mM}$ Tris- $\mathrm{Cl}$ (pH 7.5), $50 \mathrm{mM} \mathrm{KCl}$, and $250 \mathrm{mM}$ imidazole, then dialyzed into buffer Q (25 mM Tris- $\mathrm{Cl}$ at $\mathrm{pH}$ 7.5, $20 \mathrm{mM} \mathrm{NH} 4 \mathrm{Cl}, 5$ $\mathrm{mM} \beta \mathrm{ME}$ ), and further purified by FPLC, using a 6-mL Resource$\mathrm{Q}$ anion-exchange column (Amersham). RF3 was eluted with a 20$300 \mathrm{mM} \mathrm{NH} 4 \mathrm{Cl}$ gradient over $300 \mathrm{~mL}$, dialyzed into buffer A, aliquoted, quick-frozen in liquid $\mathrm{N}_{2}$, and stored at $-80^{\circ} \mathrm{C}$.

Typically, $400 \mathrm{pmol}$ of ribosomes, $600 \mathrm{pmol}$ of tRNA-Met (MP Biomedicals), and 1000 pmol of mRNA M0-27 (5'-GGCAAG GAGGUAAAAAUGUAAAAAAAA, IDT) were incubated for 20 min at $37^{\circ} \mathrm{C}$ in $20 \mathrm{mM}$ Tris- $\mathrm{Cl}\left(\mathrm{pH} \mathrm{7.0),} 100 \mathrm{mM} \mathrm{NH}_{4} \mathrm{Cl}, 21 \mathrm{mM}\right.$ $\mathrm{MgCl}_{2}$, and $1 \mathrm{mM}$ EDTA. The $\mathrm{MgCl}_{2}$ concentration was adjusted to $10.5 \mathrm{mM}$ by adding an equal volume of buffer containing 20 $\mathrm{mM}$ Tris- $\mathrm{Cl}(\mathrm{pH} 7.0)$ and $100 \mathrm{mM} \mathrm{NH}_{4} \mathrm{Cl}$, before adding 4000 pmol of RF3, GDPNP, and viomycin; and incubating for $10 \mathrm{~min}$ at $37^{\circ} \mathrm{C}$. The final solution conditions were $20 \mathrm{mM}$ Tris- $\mathrm{Cl}(\mathrm{pH}$ 7.0), $100 \mathrm{mM} \mathrm{NH}_{4} \mathrm{Cl}, 10.5 \mathrm{mM} \mathrm{MgCl}_{2}, 0.5 \mathrm{mM}$ EDTA, $1.5 \mathrm{mM}$ GDPNP, and $1.5 \mathrm{mM}$ viomycin in a volume of $100 \mu \mathrm{L}$.

\section{Crystallization}

Crystals were grown via vapor diffusion in 96-well plates by adding $3 \mu \mathrm{L}$ of reservoir solution (100 mM Tris at $\mathrm{pH} 7.0,25-35$ $\mathrm{mM} \mathrm{KCl}, 6.1 \%$ PEG20K, $1 \%$ glycerol, $50 \mathrm{mM}$ sucrose), to $1 \mu \mathrm{L}$ of sample, which results in a final concentration of $3.3 \mathrm{mM} \mathrm{MgCl}_{2}$ in the drop after equilibrium. Viomycin-free complexes were crystallized under the same conditions, except that optimal diffraction was obtained with $6.8 \%-7.2 \%$ PEG20K. After $5 \mathrm{~d}$ at $22^{\circ} \mathrm{C}$, crystals grew to dimensions of up to $300 \times 200 \times 50 \mu \mathrm{M}$ and were stabilized in a cryo-protection buffer containing $50 \mathrm{mM} \mathrm{KOAc}(\mathrm{pH}$ 5.0), 6.5\% PEG20K, 20\% PEG400, $50 \mathrm{mM}$ sucrose, $1 \%$ glycerol, 0.5 $\mathrm{mM}$ GDPNP, and $0.5 \mathrm{mM}$ viomycin. Solid $\left(\mathrm{NH}_{4}\right)_{2} \mathrm{SO}_{4}$ was then added at saturating concentration to the well solution. After $3 \mathrm{~d}$, crystals were harvested and flash-frozen in liquid nitrogen.

\section{Crystal screening and data collection}

Crystals were screened at beamline 12-2 at the Stanford Synchrotron Radiation Laboratory (SSRL) and at beamline 12-3-1 at the Advanced Light Source (ALS), Lawrence Berkeley National Laboratory. Data were collected at beamline 12-2 at the SSRL, beamline 12-3-1 at the ALS, and at beamline 23ID-D at the Advanced Photon Source at Argonne National Laboratory using $0.4^{\circ}$ oscillations. Diffraction data from four crystals were integrated, merged, and scaled in XDS (Kabsch 1993).

\section{Molecular replacement and structure refinement}

The crystal structure was solved by molecular replacement in Phaser (McCoy et al. 2007). A single ribosome was found per asymmetric unit. $30 \mathrm{~S}$ and $50 \mathrm{~S}$ subunits from a previously described structure of the E. coli 70 S ribosome in the classical state (Zhang et al. 2009) were used as the initial search model. Clear density was visible for RF3 bound with GDPNP (Supplemental Fig. S2), viomycin, the pentameric complex of proteins L10(L12 NTD) ${ }_{4}$ (Supplemental Fig. S3A), and parts of the mRNA in the $3.3 \AA F_{\mathrm{o}}-$ $F_{c}$ electron density map. Two-rigid-body refinement was performed initially in Phenix (Adams et al. 2010), revealing an $\sim 7^{\circ}$ counterclockwise rotation of the $30 \mathrm{~S}$ subunit. A further 300 -rigidbody refinement was carried out as previously described (Korostelev et al. 2008a). TLS, B group, and individual coordinate refinements were carried out in Phenix, and minimization refinement in CNS (Brünger et al. 1998) was also used to improve the model. The model was finally refined to values of $R=21.4$ and $R_{\text {free }}=25.2$.

Parts of the rRNA model, such as the flipped-out 16S rRNA bases A1492 and A1493, were initially rebuilt manually in O (Jones et al. 1991). The mRNA model was built starting with the mRNA structure from the RF1 70S ribosome complex (Laurberg et al. 2008). The initial RF3 model was from the crystal structure of free RF3 in its GDP form (Gao et al. 2007). The RF3.GDP structure was docked into the unbiased $F_{\mathrm{o}}-F_{\mathrm{c}}$ electron density map and rebuilt manually in Coot (Emsley and Cowtan 2004).

The crystal structure of $T$. thermophilus protein L10 in complex containing two of the three L12 N-terminal domain dimers (Diaconu et al. 2005) mutated into the corresponding $E$. coli sequences was used as the initial model. Manual docking into the $F_{\mathrm{o}}-F_{\mathrm{c}}$ electron density map was followed by manual fitting of the main chain and side chains in Coot and refinement in Phenix. The viomycin model from the previously determined structure of viomycin bound to the classical-state $70 \mathrm{~S}$ ribosome (Stanley et al. 2010) was used for docking into the $F_{\mathrm{o}}-F_{\mathrm{c}}$ electron density map. To confirm the positions of viomycin in the rotated ribosome, we compared $F_{\mathrm{o}}-F_{\mathrm{c}}$ map differences between RF3 70 S ribosome complex crystals with and without viomycin.

\section{Binding of RF3 to the RF2 termination complex}

Termination complexes formed with 100 pmol of ribosomes, 200 pmol of tRNA ${ }^{\mathrm{fMet}}, 300 \mathrm{pmol}$ of mRNA m0-27, and $600 \mathrm{pmol}$ of RF2, in a total volume of $40 \mu \mathrm{L}$ of buffer $\mathrm{A}$, were isolated by pelleting through $200 \mu \mathrm{L}$ of $37 \%(\mathrm{w} / \mathrm{v})$ sucrose cushion in buffer $\mathrm{A}$, in a TLA100 rotor at $100,000 \mathrm{rpm}$ for $45 \mathrm{~min}$ at $4^{\circ} \mathrm{C}$. The pellet was resuspended in $110 \mu \mathrm{L}$ of buffer A; $20 \mu \mathrm{L}(\sim 15 \mathrm{pmol})$ of termination complex was added to $60 \mathrm{pmol}$ of RF3, RF3-GDP, RF3-GTP, or RF3-GDPNP ( $1 \mathrm{mM}$ final concentration nucleotide); and incubated for $5 \mathrm{~min}$ at $37^{\circ} \mathrm{C}$, before pelleting again through a $200-\mu \mathrm{L}$ sucrose cushion in buffer A supplemented with $0.5 \mathrm{mM}$ GDP, GTP, or GDPNP as required. The pellets were resuspended in $15 \mu \mathrm{L}$ of gel-loading buffer and run on a $10 \%$ polyacrylamide SDS gel (Supplemental Fig. S10).

\section{DATA DEPOSITION}

Coordinates and structure factors have been deposited with PDB IDs 3SFS, 3SGF, 3UOQ, and 3UOS.

\section{SUPPLEMENTAL MATERIAL}

Supplemental material is available for this article. 


\section{ACKNOWLEDGMENTS}

We thank J.P. Donohue for expert computational support and for help with preparation of figures; $M$. Soltis and the staff at beamline 12-2 at the Stanford Synchrotron Light Source, S. Classen at beamline 12.3.1 at the Advanced Light Source, and M. Becker and R. Sanishvili at beamline 23-ID at the Advanced Photon Source for expert advice and support during screening and data collection; M. Laurberg for advice on restraints during crystallographic refinement; J.H.D. Cate for communicating his results prior to publication and for critical discussion; S. Joseph and D. Herschlag for critical discussions; and members of the Noller laboratory for their support. This work was supported by grants from the NIH, the NSF, the Human Frontiers Science Program, QB3, and the Agouron Foundation.

Received October 17, 2011; accepted October 31, 2011.

\section{REFERENCES}

Adams PD, Afonine PV, Bunkóczi G, Chen VB, Davis IW, Echols N, Headd JJ, Hung LW, Kapral GJ, Grosse-Kunstleve RW, et al. 2010. PHENIX: A comprehensive Python-based system for macromolecular structure solution. Acta Crystallogr D Biol Crystallogr 66: 213-221.

Agirrezabala X, Lei J, Brunelle JL, Ortiz-Meoz RF, Green R, Frank J. 2008. Visualization of the hybrid state of tRNA binding promoted by spontaneous ratcheting of the ribosome. Mol Cell 32: 190-197.

Allen GS, Zavialov A, Gursky R, Ehrenberg M, Frank J. 2005. The cryoEM structure of a translation initiation complex from Escherichia coli. Cell 121: 703-712.

Ben-Shem A, Jenner L, Yusupova G, Yusupov M. 2010. Crystal structure of the eukaryotic ribosome. Science 330: 1203-1209.

Berk V, Zhang W, Pai RD, Cate JH. 2006. Structural basis for mRNA and tRNA positioning on the ribosome. Proc Natl Acad Sci 103: 15830-15834.

Brünger AT, Adams PD, Clore GM, DeLano WL, Gros P, GrosseKunstleve RW, Jiang JS, Kuszewski J, Nilges M, Pannu NS, et al. 1998. Crystallography \& NMR system: A new software suite for macromolecular structure determination. Acta Crystallogr D Biol Crystallogr 54: 905-921.

Connell SR, Takemoto C, Wilson DN, Wang H, Murayama K, Terada T, Shirouzu M, Rost M, Schuler M, Giesebrecht J, et al. 2007. Structural basis for interaction of the ribosome with the switch regions of GTP-bound elongation factors. Mol Cell 25: 751-764.

Cool RH, Parmeggiani A. 1991. Substitution of histidine-84 and the GTPase mechanism of elongation factor Tu. Biochemistry 30: 362-366.

Cornish PV, Ermolenko DN, Noller HF, Ha T. 2008. Spontaneous intersubunit rotation in single ribosomes. Mol Cell 30: 578-588.

Cornish PV, Ermolenko DN, Staple DW, Hoang L, Hickerson RP, Noller HF, Ha T. 2009. Following movement of the L1 stalk between three functional states in single ribosomes. Proc Natl Acad Sci 106: 2571-2576.

Culver GM, Cate JH, Yusupova GZ, Yusupov MM, Noller HF. 1999. Identification of an RNA-protein bridge spanning the ribosomal subunit interface. Science 285: 2133-2136.

Diaconu M, Kothe U, Schlünzen F, Fischer N, Harms JM, Tonevitsky AG, Stark H, Rodnina MV, Wahl MC. 2005. Structural basis for the function of the ribosomal L7/12 stalk in factor binding and GTPase activation. Cell 121: 991-1004.

Dunkle JA, Cate JH. 2010. Ribosome structure and dynamics during translocation and termination. Annu Rev Biophys 39: 227-244.

Dunkle JA, Wang L, Feldman MB, Pulk A, Chen VB, Kapral GJ, Noeske J, Richardson JS, Blanchard SC, Cate JH. 2011. Structures of the bacterial ribosome in classical and hybrid states of tRNA binding. Science 332: 981-984.
Emsley P, Cowtan K. 2004. Coot: Model-building tools for molecular graphics. Acta Crystallogr D Biol Crystallogr 60: 2126-2132.

Ermolenko DN, Majumdar ZK, Hickerson RP, Spiegel PC, Clegg RM, Noller HF. 2007a. Observation of intersubunit movement of the ribosome in solution using FRET. J Mol Biol 370: 530-540.

Ermolenko DN, Spiegel PC, Majumdar ZK, Hickerson RP, Clegg RM, Noller HF. 2007b. The antibiotic viomycin traps the ribosome in an intermediate state of translocation. Nat Struct Mol Biol 14: 493497.

Fei J, Kosuri P, MacDougall DD, Gonzalez RL Jr. 2008. Coupling of ribosomal L1 stalk and tRNA dynamics during translation elongation. Mol Cell 30: 348-359.

Fischer N, Konevega AL, Wintermeyer W, Rodnina MV, Stark H. 2010. Ribosome dynamics and tRNA movement by time-resolved electron cryomicroscopy. Nature 466: 329-333.

Frank J, Agrawal RK. 2000. A ratchet-like inter-subunit reorganization of the ribosome during translocation. Nature 406: 318-322.

Frank J, Gonzalez RL Jr. 2010. Structure and dynamics of a processive Brownian motor: The translating ribosome. Annu Rev Biochem 79: 381-412.

Frank J, Gao H, Sengupta J, Gao N, Taylor DJ. 2007. The process of mRNA-tRNA translocation. Proc Natl Acad Sci 104: 19671-19678.

Freistroffer DV, Pavlov MY, MacDougall J, Buckingham RH, Ehrenberg M. 1997. Release factor RF3 in E. coli accelerates the dissociation of release factors RF1 and RF2 from the ribosome in a GTP-dependent manner. EMBO J 16: 4126-4133.

Gao N, Zavialov AV, Li W, Sengupta J, Valle M, Gursky RP, Ehrenberg M, Frank J. 2005. Mechanism for the disassembly of the posttermination complex inferred from cryo-EM studies. Mol Cell 18: 663674.

Gao H, Zhou Z, Rawat U, Huang C, Bouakaz L, Wang C, Cheng Z, Liu Y, Zavialov A, Gursky R, et al. 2007. RF3 induces ribosomal conformational changes responsible for dissociation of class I release factors. Cell 129: 929-941.

Gao YG, Selmer M, Dunham CM, Weixlbaumer A, Kelley AC, Ramakrishnan V. 2009. The structure of the ribosome with elongation factor $G$ trapped in the posttranslocational state. Science 326: 694-699.

Goldstein JL, Caskey CT. 1970. Peptide chain termination: Effect of protein S on ribosomal binding of release factors. Proc Natl Acad Sci 67: 537-543.

Jin H, Kelley AC, Ramakrishnan V. 2011. Crystal structure of the hybrid state of ribosome in complex with the guanosine triphosphatase release factor 3. Proc Natl Acad Sci 108: 15798-15803.

Jones TA, Zou JY, Cowan SW, Kjeldgaard M. 1991. Improved methods for building protein models in electron density maps and the location of errors in these models. Acta Crystallogr A 47: $110-119$.

Julian P, Konevega AL, Scheres SH, Lazaro M, Gil D, Wintermeyer W, Rodnina MV, Valle M. 2008. Structure of ratcheted ribosomes with tRNAs in hybrid states. Proc Natl Acad Sci 105: 16924-16927.

Kabsch W. 1993. Automatic processing of rotation diffraction data from crystals of initially unknown symmetry and cell constants. J Appl Cryst 26: 795-800.

Klaholz BP. 2011. Molecular recognition and catalysis in translation termination complexes. Trends Biochem Sci 36: 282-292.

Klaholz BP, Myasnikov AG, Van Heel M. 2004. Visualization of release factor 3 on the ribosome during termination of protein synthesis. Nature 427: 862-865.

Korostelev A, Noller HF. 2007. Analysis of structural dynamics in the ribosome by TLS crystallographic refinement. J Mol Biol 373: 1058-1070.

Korostelev A, Trakhanov S, Laurberg M, Noller HF. 2006. Crystal structure of a $70 \mathrm{~S}$ ribosome-tRNA complex reveals functional interactions and rearrangements. Cell 126: 1065-1077.

Korostelev A, Asahara H, Lancaster L, Laurberg M, Hirschi A, Zhu J, Trakhanov S, Scott WG, Noller HF. 2008a. Crystal structure of a translation termination complex formed with release factor RF2. Proc Natl Acad Sci 105: 19684-19689. 
Korostelev A, Ermolenko DN, Noller HF. 2008b. Structural dynamics of the ribosome. Curr Opin Chem Biol 12: 674-683.

Korostelev A, Zhu J, Asahara H, Noller HF. 2010. Recognition of the amber UAG stop codon by release factor RF1. EMBO J 29: 25772585.

Kunkel TA. 1985. Rapid and efficient site-specific mutagenesis without phenotypic selection. Proc Natl Acad Sci 82: 488-492.

Lassila JK, Zalatan JG, Herschlag D. 2011. Biological phosphoryltransfer reactions: Understanding mechanism and catalysis. Annu Rev Biochem 80: 669-702.

Laurberg M, Asahara H, Korostelev A, Zhu J, Trakhanov S, Noller HF. 2008. Structural basis for translation termination on the $70 \mathrm{~S}$ ribosome. Nature 454: 852-857.

Lieberman KR, Firpo MA, Herr AJ, Nguyenle T, Atkins JF, Gesteland RF, Noller HF. 2000. The 23 S rRNA environment of ribosomal protein L9 in the $50 \mathrm{~S}$ ribosomal subunit. J Mol Biol 297: 11291143.

Liljas A, Ehrenberg M, Åqvist J. 2011. Comment on "The mechanism for activation of GTP hydrolysis on the ribosome." Science 333: 37. doi: $10.1126 /$ science. 1202472

Maegley KA, Admiraal SJ, Herschlag D. 1996. Ras-catalyzed hydrolysis of GTP: A new perspective from model studies. Proc Natl Acad Sci 93: 8160-8166.

Marshall RA, Dorywalska M, Puglisi JD. 2008. Irreversible chemical steps control intersubunit dynamics during translation. Proc Natl Acad Sci 105: 15364-15369.

McCoy AJ, Grosse-Kunstleve RW, Adams PD, Winn MD, Storoni LC, Read RJ. 2007. Phaser crystallographic software. J Appl Crystallogr 40: 658-674.

Moazed D, Noller HF. 1989. Intermediate states in the movement of transfer RNA in the ribosome. Nature 342: 142-148.

Munro JB, Sanbonmatsu KY, Spahn CM, Blanchard SC. 2009. Navigating the ribosome's metastable energy landscape. Trends Biochem Sci 34: 390-400.

Munro JB, Altman RB, Tung CS, Cate JH, Sanbonmatsu KY, Blanchard SC. 2010. Spontaneous formation of the unlocked state of the ribosome is a multistep process. Proc Natl Acad Sci 107: 709-714.

Ogle JM, Brodersen DE, Clemons WM, Tarry MJ, Carter AP, Ramakrishnan V. 2001. Recognition of cognate transfer RNA by the 30S ribosomal subunit. Science 292: 897-902.

Pel HJ, Moffat JG, Ito K, Nakamura Y, Tate WP. 1998. Escherichia coli release factor 3: Resolving the paradox of a typical $G$ protein structure and atypical function with guanine nucleotides. RNA 4: 47-54.

Ratje AH, Loerke J, Mikolajka A, Brunner M, Hildebrand PW, Starosta AL, Donhofer A, Connell SR, Fucini P, Mielke T, et al. 2010. Head swivel on the ribosome facilitates translocation by means of intra-subunit tRNA hybrid sites. Nature 468: 713-716.

Rawat UB, Zavialov AV, Sengupta J, Valle M, Grassucci RA, Linde J, Vestergaard B, Ehrenberg M, Frank J. 2003. A cryo-electron microscopic study of ribosome-bound termination factor RF2. Nature 421: 87-90.
Rawat U, Gao H, Zavialov A, Gursky R, Ehrenberg M, Frank J. 2006. Interactions of the release factor RF1 with the ribosome as revealed by cryo-EM. J Mol Biol 357: 1144-1153.

Schmeing TM, Voorhees RM, Kelley AC, Gao YG, Murphy FVt, Weir JR, Ramakrishnan V. 2009. The crystal structure of the ribosome bound to EF-Tu and aminoacyl-tRNA. Science 326: 688-694.

Schuwirth BS, Borovinskaya MA, Hau CW, Zhang W, Vila-Sanjurjo A, Holton JM, Cate JH. 2005. Structures of the bacterial ribosome at $3.5 \AA$ resolution. Science 310: 827-834.

Selmer M, Dunham CM, Murphy FVt, Weixlbaumer A, Petry S, Kelley AC, Weir JR, Ramakrishnan V. 2006. Structure of the 70S ribosome complexed with mRNA and tRNA. Science 313: 19351942.

Spahn CM, Gomez-Lorenzo MG, Grassucci RA, Jorgensen R, Andersen GR, Beckmann R, Penczek PA, Ballesta JP, Frank J. 2004. Domain movements of elongation factor eEF2 and the eukaryotic $80 \mathrm{~S}$ ribosome facilitate tRNA translocation. EMBO J 23: 1008-1019.

Spiegel PC, Ermolenko DN, Noller HF. 2007. Elongation factor G stabilizes the hybrid-state conformation of the 70S ribosome. RNA 13: $1473-1482$.

Stanley RE, Blaha G, Grodzicki RL, Strickler MD, Steitz TA. 2010. The structures of the anti-tuberculosis antibiotics viomycin and capreomycin bound to the 70S ribosome. Nat Struct Mol Biol 17: 289293.

Stark H, Rodnina MV, Wieden HJ, van Heel M, Wintermeyer W. 2000. Large-scale movement of elongation factor $G$ and extensive conformational change of the ribosome during translocation. Cell 100: 301-309.

Valle M, Zavialov A, Sengupta J, Rawat U, Ehrenberg M, Frank J. 2003. Locking and unlocking of ribosomal motions. Cell 114: 123134.

Voorhees RM, Schmeing TM, Kelley AC, Ramakrishnan V. 2010. The mechanism for activation of GTP hydrolysis on the ribosome. Science 330: 835-838.

Weixlbaumer A, Jin H, Neubauer C, Voorhees RM, Petry S, Kelley AC, Ramakrishnan V. 2008. Insights into translational termination from the structure of RF2 bound to the ribosome. Science 322: 953-956.

Wittinghofer A, Vetter IR. 2011. Structure-function relationships of the G domain, a canonical switch motif. Annu Rev Biochem 80: 943-971.

Yusupov M, Yusupova G, Baucom A, Lieberman K, Earnest TN, Cate JH, Noller HF. 2001. Crystal structure of the ribosome at $5.5 \AA$ resolution. Science 292: 883-896.

Zavialov AV, Buckingham RH, Ehrenberg M. 2001. A posttermination ribosomal complex is the guanine nucleotide exchange factor for peptide release factor RF3. Cell 107: 115-124.

Zavialov AV, Mora L, Buckingham RH, Ehrenberg M. 2002. Release of peptide promoted by the GGQ motif of class 1 release factors regulates the GTPase activity of RF3. Mol Cell 10: 789-798.

Zhang W, Dunkle JA, Cate JH. 2009. Structures of the ribosome in intermediate states of ratcheting. Science 325: 1014-1017. 

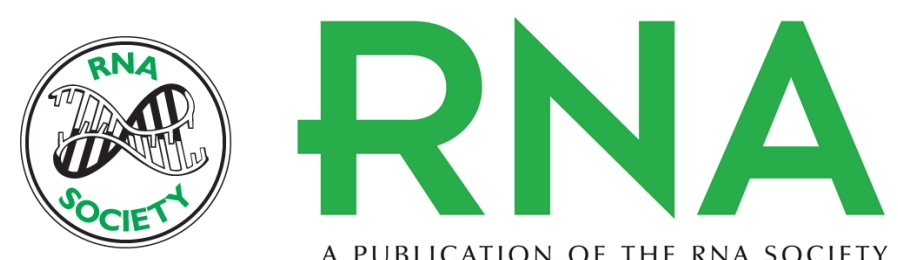

A PUBLICATION OF THE RNA SOCIETY

\section{Crystal structure of release factor RF3 trapped in the GTP state on a rotated conformation of the ribosome}

Jie Zhou, Laura Lancaster, Sergei Trakhanov, et al.

RNA 2012 18: $230-240$ originally published online December 20, 2011

Access the most recent version at doi:10.1261/rna.031187.111

Supplemental http://rnajournal.cshlp.org/content/suppl/2011/12/06/rna.031187.111.DC1
Material

References This article cites 69 articles, 28 of which can be accessed free at:

http://rnajournal.cshlp.org/content/18/2/230.full.html\#ref-list-1

License

Email Alerting Receive free email alerts when new articles cite this article - sign up in the box at the Service top right corner of the article or click here. 